\title{
International benchmark and best practices on national infrastructure plans. Application to Spanish strategic planning.
}

\author{
Eva María Pino Hernández \\ Manager. Policy and Planning Area. INECO, Spain \\ Cristina Delgado Quiralte \\ Senior Technical Manager. Policy and Planning Area. INECO, Spain
}

\begin{abstract}
The need for planning regarding investment in infrastructures is recognised and supported by most governments around the world. Planning helps to take effective and correct decisions, provides a basis for monitoring its impacts and also facilitates further developments. However it requires a high level of organization, coordination among stakeholders and anticipation of transport needs.
\end{abstract}

There are some different methodological approaches for strategic planning. This paper examines the importance of infrastructure planning and how it is undertaken in different countries from Europe and other continents. It is based on a benchmarking about planning procedures of 7 reference countries (UK, France, the Netherlands, Poland, Germany, Japan and USA), in addition to others whose strategic plans are being developed at the present moment such as Croatia or Romania. This benchmarking aims to extract and compare best practices carried out in this field and to define the optimal formulation of strategic planning. In this regard, the benchmarking is focused on some key aspects: firstly, on the plan structure and its main contents. There are a lot of differences about how each country defines the future needs for transport and how it establishes the objectives and the strategies to be followed. Secondly, on the characterisation of the authorities which are responsible of the plan development (level of dependence from the government, know-how...) along with the time frame and final validity of the plans. And finally, the level of detail of the proposed actions and budgetary commitments provided by the strategic plans.

Throughout the comparative analysis, the knowledge generated by this benchmarking has allowed setting a series of specific recommendations in strategic planning which can be applied as innovative solutions and best practices in future planning processes in Spain.

\section{THEORETICAL FRAMEWORK}

\subsection{The importance of strategic planning of transport systems and infrastructure}

Strategic planning is the process by which plans are formulated in order to achieve specific objectives, in the medium and long term, through the implementation of certain policies and 
actions. Moreover, by the monitoring and measurement of the plan results, key tools are obtained to assess the achievement of these objectives.

In regard to the development of transport infrastructures, which involve large investments and generate strong impacts, the planning process is particularly important. Therefore, its approach should be addressed from three different points of view: land planning, socioeconomic development and environmental protection. This triple perspective allows that the strategic infrastructure plans highlight the needs of the territory, contributing to the decision-making process by giving it greater coherence and effectiveness, and allowing the monitoring of impacts generated by its implementation in all areas. The final goal of these planning tools is to achieve balanced territories, without inequalities, that accomplish the necessary conditions to create a cohesive society.

\subsection{Objectives}

This paper is based on the analysis of the existing instruments of strategic planning in different representative countries. The objectives to be pursued through this analysis are the following:

- Study different planning processes, determine the degree of detail of the actions proposed in other countries and compare budgetary commitments acquired;

- Extract the best practices carried out in planning processes and define the optimal strategic planning of infrastructure;

- Get a set of recommendations applicable to our country in order to propose solutions and most innovative practices in future planning processes.

\subsection{Working methodology}

To meet these objectives, it is necessary to establish a methodology. It must start from the analysis of the current Spanish strategic planning, as well as the latest planning instruments developed, in order to compare the planning method followed between Spain and other countries.

Once characterized the Spanish strategic planning regarding transport infrastructures, it has proceeded to analyse planning process followed in the 7 countries which have been considered as reference cases, due to their strategic tradition or because they have some similarities with our country.

Table 1 contains the 7 countries selected for this study and summarizes the planning instruments analysed for each one. 


\begin{tabular}{|l|l|}
\hline Analysed country & Planning instruments analysed \\
\hline Germany & $\begin{array}{l}\text { Federal Transport Infrastructure Plan 2003 } \\
\text { Forecast of transport interconnectivity 2015 }\end{array}$ \\
\hline France & Schéma National des Infrastructures de Transport 2011 \\
\hline Netherland & $\begin{array}{l}\text { National Policy Strategy for Infrastructure and Spatial Planning } \\
2013\end{array}$ \\
\hline Poland & National Development Strategy 2006 \\
\hline United Kingdom & $\begin{array}{l}\text { National Infrastructure Plan 2010 } \\
\text { National Infrastructure Plan updated versions 2011-2014 }\end{array}$ \\
\hline Japan & White Paper on Land, Infrastructure, Transport and Tourism 2013 \\
\hline United States & Transportation for a new generation. Strategic Plan I 2014 \\
\hline
\end{tabular}

\section{Table 1 - Planning instruments analysed}

In addition, some preliminary versions of strategic plans that are currently under development have been studied, such as the plan of Romania (Romania General Transport Master Plan) or the future strategic plan of Croatian (National Strategic Reference Framework 2013). For all of them a detailed description of the contents and strategy has been undertaken, with particular emphasis on the following aspects:

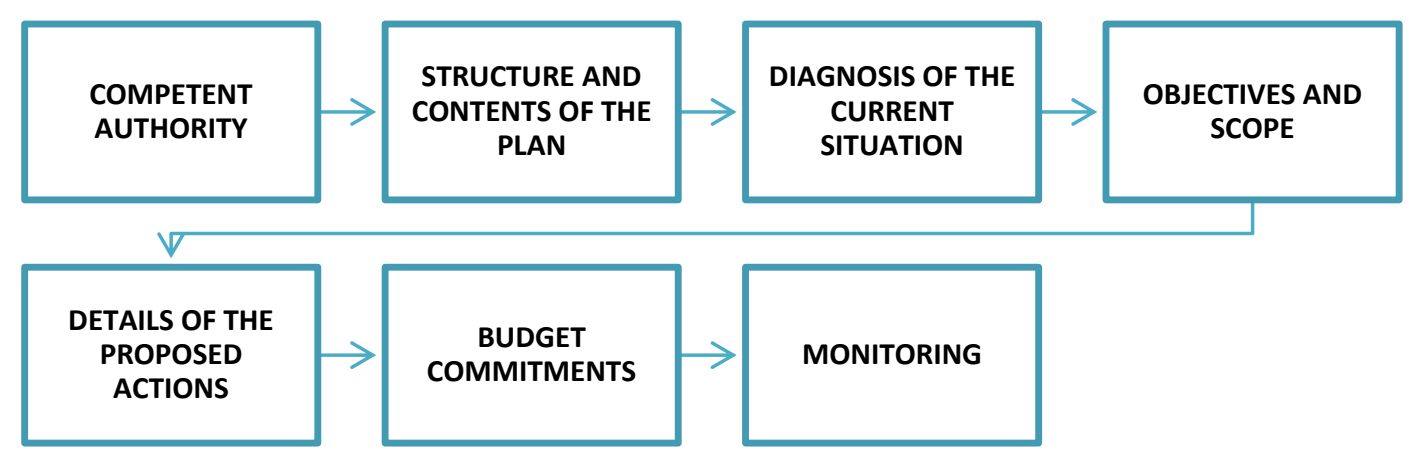

Fig. 1 -Key issues to be assessed in the strategic planning instruments

The examination of all these key aspects allows drawing a number of recommendations and best practices to be applied in planning processes. Finally, the comparative analysis with the Spanish case has as a result a series of proposals that will let to improve significantly the Spanish strategic planning for transport infrastructure in the future.

\section{INTERNATIONAL BENCHMARKING: PLANNING INSTRUMENTS ANALYSIS BY COUNTRY}

The comparative analysis described above has allowed knowing the scope and contents of the strategic plans and the detail of the actions proposed in other countries, as well as their financing methods. In this regard, some conclusions have been extracted, as summarized below: 


\subsection{Competent Authority and plans' structure \& contents.}

National planning in transport is generally required by law, being responsibility of a public agency under the competent Ministry or Ministries. However, strategic infrastructure plans are not mandatory; it is not required to comply strictly with the proposed actions and their budget estimates, although in practice the provision of public funds for infrastructure depends on the establishments of these documents. Any case, regardless of the territorial organization of each country (political-administrative division according to Autonomous Communities, Regions...) it is considered more beneficial to define a budget plan of actions coordinated for the whole territory in order to avoid limitations by the jurisdictional structure of the State.

In terms of contents, most of the plans analysed include the definition of objectives, proposals for action and monitoring tasks. However, some of them do not contain a diagnosis of the current situation about the transport system, setting their objectives and actions basing on an independent document, which can be made or not by the same agency. This is the case of the planning instruments of UK, Netherland, Germany and the US, which provide some general data about socioeconomic issues or transport demand; while others, such as the documents of France and Poland, do contain a summary of the diagnosis as an annex. It should be noted that the development of a diagnosis as an independent document streamlines the planning process and allows reducing the time frame. In shorter terms, planning process becomes more dynamic, providing the ability to adapt to changing situations and facilitating the subsequent process of evaluation and monitoring of the actions proposed.

\subsection{Establishment of the objectives}

The set of objectives defined in the plan describes the chosen direction by a territory regarding the development of its transport system. The definition of these goals is usually a result of a preliminary analysis of the actual situation, whose diagnosis highlights the problems and needs related to transport. As said before, this diagnosis is not always within the contents of the plan, but it is certainly the basis on which these documents should support, since the definition of its objectives is based on identifying how to resolve these deficiencies.

It should be noted that some plans distinguish between strategic goals and specific objectives, which are set out by sector, strategic lines or even by transport modes. Usually, about five or six strategic objectives are defined, although not in detail. Most strategic plans studied have similar strategic objectives related to the optimization of infrastructures, generally aligned to the European directives. Other common objectives are related to promote economic competitiveness and ensure the welfare state.

On the other hand, the specific objectives are usually more numerous and defined in much more detail. For instance, the strategic plan of Germany devotes an entire chapter to the definition of its 9 specific objectives. Instead, the US document attributes to each strategic objective a series of specific goals for their development. 
Only the French document does not include specific objectives, justifying briefly each of its 5 general objectives defined.

\subsection{Scope and time frame}

The objectives set in a plan are usually defined in time in order to materialize them into real actions, avoiding they turn into mere intentions. Among the strategic plans studied, most of them have a time frame of 15 years, some even higher, as the strategic plan of France. By contrast, documents of UK and the US have the shortest time horizons, with 5 and 4 years respectively.

\subsection{Proposals for action and funding methods}

The way of describing the action programs, which are defined with the aim of achieving the stated objectives, also shows important differences among the plans analysed. At this point it should be noted that there are different types of plans; those that are related only to transport infrastructure, as in the case of France, Germany or the US; and the multisectoral plans, which also include issues related to housing, telecommunications, energy, the environment, etc. such as the instruments developed in Spain, UK, the Netherlands, Poland or Japan. Therefore, actions can be grouped and described by sector and/or by transport mode. In some cases they are classified according to the objectives pursued, such as the Dutch document, which provides a list of concrete actions, ongoing or planned, for each of the 13 specific objectives defined in the plan.

The level of detail in the definition of the action programs is also very variable. Some documents involve extremely generic actions, almost guidelines, while others detail them showing their deadlines and investment needs, among other features, such as in Germany and France.

Anyway, it is of particular interest to distinguish between actions focused on servicing and maintenance of infrastructure and actions about new infrastructures. In this regard, investment priorities should be established, giving priority to those that are clearly justified by their economic and social profitability or their relevance without any budget constraints. The establishment of investment priorities also facilitates the adjustment between the budgetary commitments and the final investments in the future. The strategic plans of France, Germany and UK are good examples of prioritizing actions.

Regarding financing methods, all the cases analysed highlight the importance of the privatepublic partnership models (PPP) for the development of large infrastructure projects.

\subsection{Evaluation and monitoring tasks}

The evaluation and monitoring processes are the instruments to know if the development of the planned actions is being carried out according to the intended objectives. It provides formality and rigor to the strategic plan and facilitates its update. 
These tasks are deeply linked to the decision-making process, allowing redefine goals, make adjustments in the planned measures and introduce improvements in the plan. To optimize them, it is important to define a number of key indicators for each sector analysed (security, performance, cost...). They should be periodically measure in order to examine the impact of the planning process. In this regard, the new technologies can play an important role, so it is important to concentrate efforts to promote their development. The strategic plan of UK is the best example in terms of evaluating and monitoring the results. With a methodology based on indicators, this document (which is updated annually) also indicates the status and progress in each of the 40 priority actions contemplated.

Finally, it should be noted that new technologies are also very useful to promote transparency and citizen participation in the whole process. A notable example is the case of the strategic plan of the Netherlands that is complemented by a website where users can find information about the actions planned by the authorities and their state. In addition, these monitoring and evaluation tasks are delegated to an independent agency.

\subsection{Particularities of the strategic planning process in Spain}

One of the main features of the strategic planning of infrastructure in our country is that plans are updated practically every new legislature, which greatly hinders the realization of the planned actions.

Another remarkable feature of the recent Spanish planning is that plans usually include a detailed diagnosis of the current situation. This diagnosis contains a comprehensive analysis about the existing infrastructures and services, the current transport demand and forecast for both passengers and freight transport, the management models and their regulatory framework, as well as many other aspects such as the environmental effects of transport sector. This is a necessary step to establish the basis for planning policy, but it is quite laborious and tedious so that it often slows down the whole process. For this reason, the plan sometimes is affected by changes in the evolution of the transport system during the drafting process.

Finally, the strategic plans in Spain are also characterized by defining action programs without indications of prioritization.

\section{CONCLUSIONS AND RECOMMENDATIONS APPLICABLE TO THE SPANISH PLANNING PROCESS}

\subsection{Recommendations applicable to the Spanish planning process}

Regarding the validity of the strategic plans in Spain, it is considered that the process would be more efficient and competent if their management was completely dissociated from the changes of government, working on a consensus document among all parliamentary 
representations, preserving some continuity.

In regard to the fact that the development of diagnosis slows down the final publication of the plan, a possible improvement could be the development of a separate diagnosis, as in the case of some countries studied, by a ministerial agency or another external body. It could be very interesting if the strategic plan was based on information from reliable statistics sources in our country, such as the Observatory of Transport and Logistics in Spain (OTLE). Such information could provide a basis for updating the strategic plan more frequently. Consequently, the planning process could be streamlined considerably, increasing its ability to adapt to changing situations. It would also facilitate the evaluation and monitoring processes, allowing proving if the planned actions are reaching the established objectives.

Related to the definition of the proposed actions, in addition to increase their level of detail (deadlines, investment needs, etc.), it would be of great interest to introduce the methodology used in other countries such as France, Germany and the UK, based on the prioritization of actions, placing as priority those that are justified socioeconomically, and leaving a second level those whose investment needs exceed the framework of financing planned for the period planned.

Finally, another aspect that should be reinforced in Spanish planning is the use of the new technologies. Currently there are multiple options (mobile applications, websites, GIS tools, etc.) that promote transparency and citizen collaboration during the public participation stage and the whole process, providing information about the progress in the development of the plan. Likewise, Intelligent Transportation Systems (ITS) such as Advanced Passenger Information Systems of Advanced Systems for Management (traffic, fleet, public transport systems...) are, in many cases, an advantageous alternative over the investment in new infrastructure. Their benefits are related to different areas such as security, savings in time and costs or economic growth and productivity. Therefore, it is an aspect that should be addressed in detail in future strategic plans.

\section{REFERENCES}

Federal Ministry of Transport and Digital Infrastructure, (2003). Federal Transport Infrastructure Plan. Germany's Government, Germany.

Ministerstwo Rozwoju (2006) National Development Strategy. Poland's Government, Poland.

Infrastructure UK, (2010). National Infrastructure Plan. Government of UK, United Kingdom.

Infrastructure UK, (2014). National Infrastructure Plan. Government of UK, United Kingdom. 
Direction Générale des Infrastructures, des Transports et de la Mer, (2011). Schéma National des Infrastructures de Transport-SNIT. Ministère de l'Écologie, du Développement durable, des Transports et du Logement, France.

Ministry of Infrastructure and the Environment, (2013). National Policy Strategy for Infrastructure and Spacial Planning. The Netherlands' Government, the Netherlands.

MILT, (2013). White Paper on Land, Infrastructure, Transport and Tourism in Japan. Ministry of Land, Infrastructure, Transport and Tourism, Japan.

U.S. Department of Transportation, (2014). Transportation for a new generation. Strategic Plan I. Federal government of the United States, USA.

Ministerio de Fomento, (2015). Plan de Infraestructuras, Transporte y Vivienda 2012 2024. Gobierno de España, Spain. 